\title{
The influence of vessel movements on the energy expenditure of fishermen in relation to activities and occupational tasks on board
}

\author{
Tomas Breidahl $^{1}$, Michael Christensen ${ }^{2}$, Jørgen Riis Jepsen ${ }^{3}$, Øyvind Omland ${ }^{1}$ \\ ${ }^{1}$ Department of Occupational Medicine, Aalborg University Hospital, Aalborg, Denmark \\ 2Department of Occupational Medicine, Aarhus University Hospital, Aarhus Denmark \\ ${ }^{3}$ Centre of Maritime Health and Society, University of Southern Denmark, Esbjerg, Denmark
}

\begin{abstract}
Background: Previous studies of professional fishing activities have indicated that vessel movements correlate to fishermen's energy expenditure. We have previously demonstrated that even in calm weather, the heel and pitch significantly increase the fishermen's energy expenditure, ignoring the activities carried out on board. This continuation of the study goes further by exploring the relation between the exposure to the ship's movements and the fishermen's energy expenditure during various physical activities on board. Materials and methods: Four fishermen on 2 contemporary steel trawlers recorded their work activities on an hourly basis during a 4 days fishing voyage. The energy expenditure was estimated with a body monitoring system (SenseWear Pro 3) carried as an armband, placed on the right upper arm. The vessels' movements were assessed by a gyroscope placed in the wheelhouse. The additional energy expenditure relative to the energy expenditure during sleep was recorded during activities such as navigation, fishing, and machine handling and was correlated to the vessels' recorded movements (pitch/roll). Data were analysed by linear regression.

Results: Roll and pitch were less than $10^{\circ}$ for both vessels during the voyages. The fishermen's energy expenditure differed with the tasks undertaken and correlated with the vessels' movements, but for navigation and fishing the correlation was only significant in the highest - fourth quartile of - pitch/roll. Conclusions: This study has demonstrated that vessel's movements in calm weather increase the energy expenditure during navigation, fishing, and machine handling and that the relation differs in between these activities on board and rest.
\end{abstract}

(Int Marit Health 2015; 66, 4: 196-202)

Key words: calm weather, fishing, energy expenditure, occupational tasks, vessel movements

\section{INTRODUCTION}

Maintaining balance during activities such as standing, walking or working on a fishing vessel's slippery and rolling deck at sea, with regular and occasional major and unpredictable motions, requires a larger muscular effort than when staying at a stable platform. These circumstances may influence the crew's energy expenditure on board and interfere with the crew's task performance, perceived effort and wellbeing in terms of e.g. motion sickness. Disturbed sleep and fatigue are also linked to stay aboard a vessel exposed to the impact of waves and whether [1, 2].

Previous studies of the oxygen uptake during various physical loads and working tasks of fishermen [3] have shown that the mere movement of the ship may increase the oxygen consumption by up to $70 \%$ at rough seas [4, 5], and that this level renders the fishermen's workload comparable to that of the heaviest industrial trades [6-10]. An oxygen uptake above $1.75 \mathrm{~L} / \mathrm{min}$ reflecting extremely heavy work has been reported in fishing [11]. This is in accordance 
Table 1. Demographics of the studied subjects

\begin{tabular}{|c|c|c|c|c|c|}
\hline Vessel & Position on board & Age [years] & Height $[\mathrm{cm}]$ & Weight [kg] & Body surface $\left[\mathrm{m}^{2}\right]^{*}$ \\
\hline \multirow[t]{2}{*}{ Polaris } & Skipper & 53 & 196 & 126 & 2.58 \\
\hline & Apprentice & 23 & 185 & 82 & 2.06 \\
\hline \multirow[t]{2}{*}{ Luna } & Fisherman & 45 & 180 & 88 & 2.08 \\
\hline & Machinist & 37 & 183 & 80 & 2.02 \\
\hline
\end{tabular}

with the reported tiredness, as well as increased heart rate and catecholamine release during fishing, which has been classified as "an extreme occupation" [3, 12].

The few studies of energy expenditure during fishing operations, however, are rather old, and for several reasons may not reflect the current situation. Contemporary fishing in Denmark is highly mechanised and much less strenuous than previously, e.g. hauling the nets, shovelling ice in the hold, and filling the catch into the hold. Furthermore, today's fishing vessels tend to be larger and better constructed in terms of maintaining balance and stability during a voyage and during fishing. Compared to previously, fishermen are consequently now likely to be less physically affected by the vessel's movements than before. In spite of the improved construction of fishing vessels, however, the influences of weather such as wind, temperature, waves, and the ship's propulsion through the water, may still impose continuous strain to the fisherman during work, and the total energy expenditure during work on board may be affected by the proportion of energy expenditure required for keeping balance during the work. These effects, of course, are likely to be more significant in rough seas.

In a previous study of the crude relation between the energy expenditure of the fishermen and the ships' movement during a voyage in calm weather, we found that the amount of heel and pitch correlated with the fishermen's energy consumption [13], ignoring the tasks undertaken on board.

The present study aims to analyse the crude relation between the ships' movement to the fishermen's energy expenditure during various activities and work tasks undertaken on board in calm weather conditions.

\section{MATERIAL AND METHODS}

\section{STUDIED FISHERMEN}

The participants were recruited with assistance from Hirtshals Fishermen's Association. The owners (skippers) of 2 steel trawlers (Polaris HG 352 and Luna HG 350) and their crew (9 fishermen) were invited to participate in the study. Two out of 5 fishermen from Polaris and 2 out of 4 fishermen from Luna participated during the whole study (Table 1). All participants were right handed males and smokers. None of them took any medication nor suffered from any known disease. The demographic characteristics of the participants are illustrated in Table 1.

\section{VESSELS}

Both vessels were relatively new steel trawlers: Luna HG 350, constructed in 1998 at Tjörn Varvet, Rönnäng, Sweden, had a gross tonnage is 306 tons, length $28.44 \mathrm{~m}$, beam 8.20 m and sticks 6.65 m. Polaris HG 352, delivered in 2003 from Vestværftet ApS, Hvide Sande, Denmark, had a gross tonnage of 173.3 tons, length $23.50 \mathrm{~m}$, beam $7.00 \mathrm{~m}$ and sticks $5.62 \mathrm{~m}$ from the level of the shelter deck.

\section{MEASUREMENTS OF THE VESSELS' MOVEMENTS}

A gyroscope $(30 \times 30 \times 20 \mathrm{~cm})$ with 2 built-in sonar sensors (Taeko scl-30a1, Foruna industries, Esbjerg) was placed in the wheelhouses of the 2 vessels. Both wheelhouses were located near the centre of the vessels. The gyroscope was connected to a handhold computer that was set to register each second the ship's movements in 2 planes (rolls from side to side and pitch from fore to aft). Prior to the measurements, the clock on the apparatus for measuring the energy consumption (see below) was synchronised with the time set on the computer on board. The simultaneously acquired 2 sets of data on roll and pitch were logged by computer software delivered by Picolog, Pico Technology (http://www. picotech.com/data-logging-software.html). Shifts in either direction were both stated as positive numbers.

The gyroscopic measurements were performed during fishing expeditions in the North Sea off the coast of Bergen, Norway. Recordings on Polaris were made from July $20^{\text {th }}$ 2010 at midnight until July $25^{\text {th }} 2010$ at 04.00 am and on Luna from October $2^{\text {nd }} 2010$ at 8.21 pm until October $6^{\text {th }}$ 2010 at $10.02 \mathrm{pm}$.

The weather conditions at both voyages were calm. Polaris experienced wind velocities up to $10 \mathrm{~m} / \mathrm{s}$ and an average air temperature of $14^{\circ} \mathrm{C}$, while Luna sailed with wind speeds up to $14 \mathrm{~m} / \mathrm{s}$ and temperatures about $12^{\circ} \mathrm{C}$.

\section{REGISTRATION OF ACTIVITIES}

For each hour, the 4 participants recorded their activities (sleep, navigation, fishing, machine handling). Sleep was registered when sleeping or trying to sleep. Navigation was registered when staying in the wheelhouse was the 


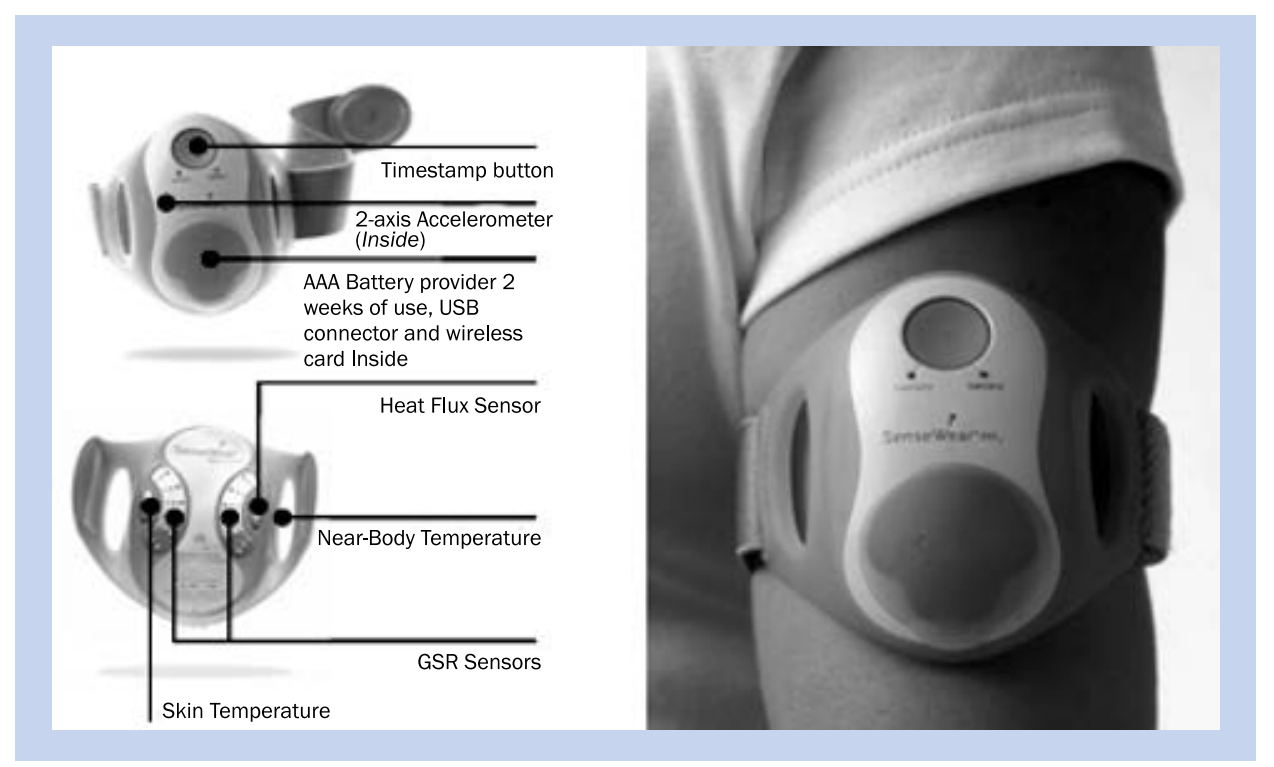

Figure 1. SenseWear apparatus

dominant activity. Machine handling was only registered by 1 person undertaking tasks in the machine room. Fishing was registered for cleaning the catch, which took place in designated rooms below deck.

\section{MEASUREMENTS OF THE ENERGY EXPENDITURE}

Information about the body's accelerations in 2 axes, the body temperature, the near-body temperature, the heat flux, and the skin's galvanic response was collected and analysed by a versatile monitoring system carried as an armband (Fig. 1) placed at the surface of the upper right arm (SenseWear Pro 3 developed by BodyMedia). The analyses of these data by the software SenseWear professional 6.1 (http:// //templehealthcare.vordpress.com/the sensewear-armband) permitted calculation of the energy expenditure by the hour for each fisherman. By additionally estimating activities such as sleep, supine position and steps taken, the programme therefore permits verification of the fishermen's information about their activities.

Due to the influence on the energy expenditure of anthropometric characteristics of the participating fishermen, we have standardised the energy expenditure according to their body surface, thereby making the measurements comparable (Table 1).

For each seafarer, we have compared the lowest energy expenditure registered during sleep to the expected basal metabolic rate (BMR). BMR is the rate of energy expenditure at rest and depends on the height, weight and age. BMR can be estimated by the Revised Harris-Benedict Equation for men: $\operatorname{BMR}(\mathrm{kcal} /$ day $)=88.362+(13.397 \times$ weight in $\mathrm{kg})+$ $+(4.799 \times$ height in $\mathrm{cm})-(5.677 \times$ age in years $)$.

\section{EXPOSURE}

The fishermen's exposure to the ships movements consists of three major indices: 1) the magnitude of the ship's roll, 2) the magnitude of the ship's pitch, and 3) the frequency of roll and pitch, respectively.

Evidently, a high frequency of roll and/or pitch is associated with low amplitude of roll and/or pitch, respectively, and vice versa. For that reason, a measure of exposure cannot be defined by combining these measures by simple addition.

To overcome this challenge, we have developed an exposure matrix that expresses what we regard as a relevant marker of exposure: the addition for each hour of the maximal angular velocity (upper quartile) in degrees for roll and pitch in both directions, respectively. We have regarded the highest value of the simultaneously recorded parameters (roll and pitch) at a certain time as the most reliable measure for the ships' movement. Therefore, these measures have served as the hourly exposure indices.

\section{STATISTICS}

The indices for exposure, i.e. the ships' movements summarised for every hour, were transferred as comma separated files and analysed by SAS statistical software. These data were synchronised in time with the energy expenditure measured by the SenseWear apparatus, thereby making correlations possible. The energy consumption for each activity was analysed in quartiles.

To avoid overlap of activities in the registration periods, we have removed the first and the last hour in the hourly registration periods where possible. This could be done for sleep, navigation and fishing, but not for machine handling. 
Table 2. Hourly energy expenditure for each activity ( $N=$ number of observations)

\begin{tabular}{llllll}
\hline Activity & N & Minimum & Mean & Maximum & Standard deviation \\
\hline Sleep & 53 & 83.4 & 89.1 & 101.1 & 4.23 \\
Navigation & 69 & 87.1 & 143.0 & 475.4 & 61.72 \\
Machine & 7 & 200.2 & 305.6 & 454.6 & 94.61 \\
Fishing & 37 & 248.9 & 337.9 & 477.4 & 67.32
\end{tabular}

The following numbers of hourly (actually analysed) registrations was for sleep: 107 (53), navigation: 95 (69), machine: 7 (7), and fishing: 99 (37), respectively (Table 2).

The exposure indices with each activity were compared on an hourly basis to the measured energy expenditure, which has been adjusted according to the body surface of the fishermen (Table 1). Analyses were performed by linear regression.

\section{RESULTS}

The exposure in terms of starboard to portside rolls and fore to aft pitch is illustrated in a time scale with plots for every average hour (Figs. 2, 3). Both were of limited magnitude and at any time less than $10^{\circ}$.

The actually lowest measured energy expenditure at sleep (calories/hour) and the estimated BMR/h for each fisherman (brackets) were close to each other: Skipper: 99.8 (100.7), apprentice: 80.1 (81.0), fisherman: 79.3 (78.2), machinist: 76.9 (76.2).

The minimal, average and maximal hourly energy expenditure during the 4 day voyages for each activity are showed in Table 2. The mean energy expenditures are illustrated in Figure 4.

There was a great variation in the energy expenditures during the various activities (Fig. 4) but less so for sleep, with $50 \%$ of the values in the interval 86.3

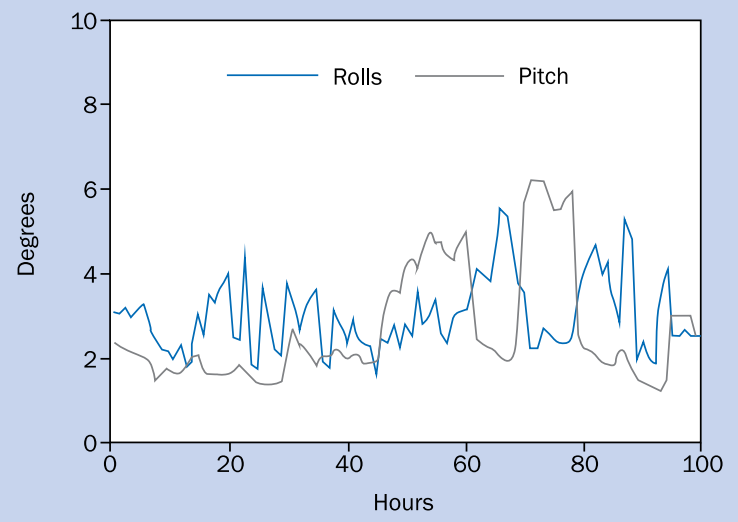

Figure 2. Hourly recorded exposure Polaris

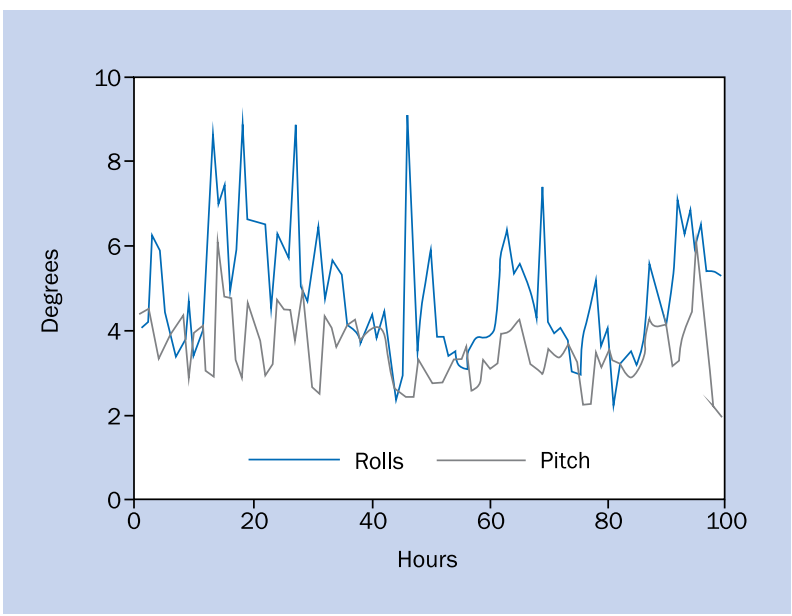

Figure 3. Hourly recorded exposure Luna

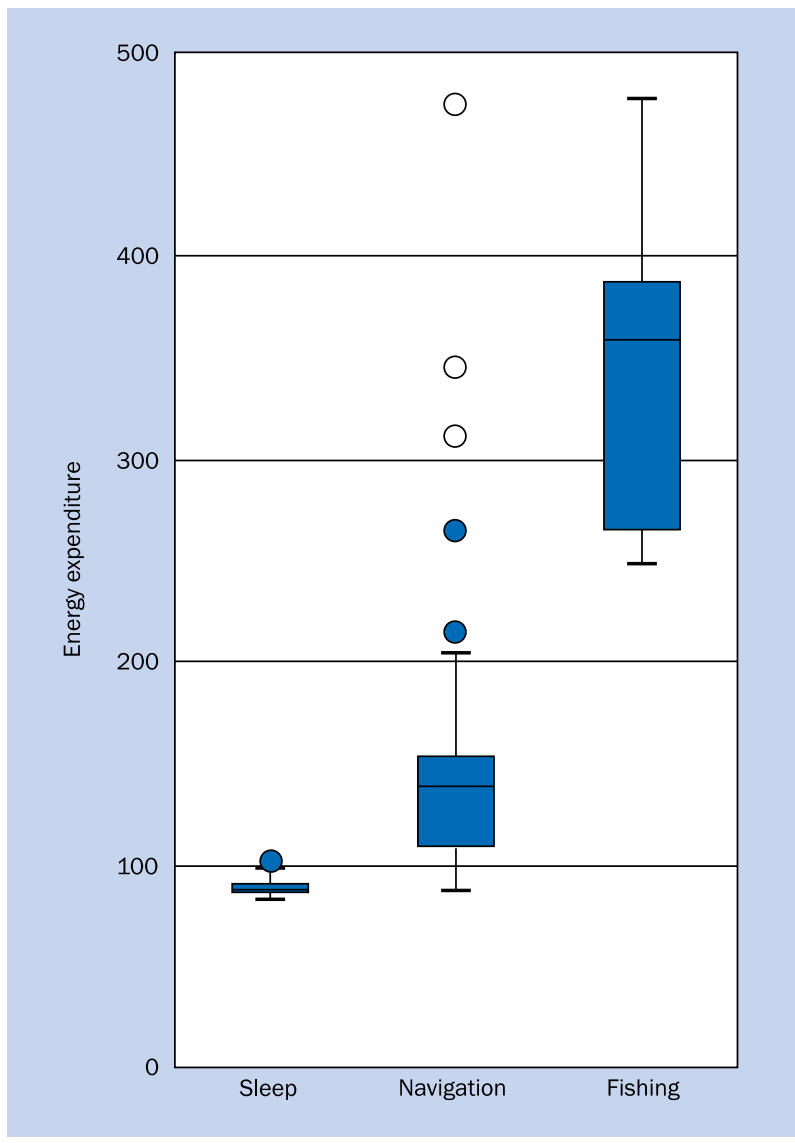

Figure 4. Distribution of energy expenditure during various activities 
to 91.2 calories/h reflecting this activity to be a rather homogeneous. For navigation, high energy expenditures were registered, although $50 \%$ of measurements were within the range of 109.6-150.6 calories/h. For machine handling there were too few observations $(n=7)$ for quartile analysis of the energy expenditure. Fishing resulted in generally higher energy expenditures with fewer higher values and 50\% of the observations between 266.3 and 387.8 calories/h thus reflecting the energy demands of this activity.

In contrast to the energy expenditure during navigating and fishing, there was no significant difference in energy expenditure while sleeping in any quartiles. For both activities there was a significant relation ( $p=0.004$ for navigation and $p=0.037$ for fishing, respectively) to the ships' movement defined as the upper $4^{\text {th }}$ quartiles for rolls and pitch (Table 3 , Figs. 5A, B).

The 7 observations for machine handling were associated to ships movement rolls and pitch in a significant dose-response manner ( $p=0.034$, data not showed).

\section{DISCUSSION}

The fishermen's energy expenditure was associated to the ships movement defined by rolls and pitch (minor than $10^{\circ}$ ) for all measured activities except sleep. Sleeping $(\mathrm{N}=53$ ) on a fishing vessel in calm weather did not influence the energy expenditure which was measured to 83.1-101.1 kilocalories/day. These figures are almost identical to the BMR as calculated in the present study. For navigation $(\mathrm{N}=69)$ there was a quite wide span in the energy expenditure (87.1-475.4 kilocalories/day) and the same was the case for fishing ( $N=37 ; 248.9-477.8$ kilocalories/day). A significant association to the ships' movement defined by rolls and pitch was only observed in the highest $4^{\text {th }}$ quartile. This indicates that low energy-consuming activities are less influenced by minor ship movement than higher energy consuming activities for which the ship's movement defined by rolls and pitch in itself requires an amount of energy expenditure.

Although we have tried to minimise the overlap of recorded activities by removing the first and the last hour of an observation period, misclassification of activities might have been introduced. Although we have no reason to believe that misclassification is more likely with a high than low energy expenditure, differential misclassification cannot completely be ruled out.

In the same way as for the activities navigation and fishing, machine handling $(\mathrm{N}=7 ; 200.2-454.6$ kilocalo-

Table 3. The energy expenditure in quartiles and pitch and rolls for the activities sleep, navigation, and fishing

\begin{tabular}{llllll}
\hline Quartile & $\mathbf{n}$ & $\mathbf{r}^{\mathbf{2}}$ & $\mathbf{A}$ & $\mathbf{P}$ & $\mathbf{B}$ \\
\hline Sleep & & & & & \\
1 & 14 & 0.010 & -0.099 & 0.734 & 85.527 \\
2 & 13 & 0.001 & 0.011 & 0.902 & 87.110 \\
3 & 13 & 0.197 & 0.378 & 0.128 & 87.351 \\
4 & 13 & 0.000 & -0.017 & 0.965 & 95.616 \\
Navigation & & & & & \\
1 & 18 & 0.159 & -1.830 & 0.102 & 107.856 \\
2 & 17 & 0.003 & -0.181 & 0.849 & 120.112 \\
3 & 17 & 0.042 & 1.753 & 0.431 & 131.217 \\
4 & 17 & 0.444 & 43.752 & 0.004 & 34.000 \\
Fishing & & & & & \\
1 & 10 & 0.013 & -0.449 & 0.755 & 258.590 \\
2 & 9 & 0.637 & -22.275 & 0.010 & 427.631 \\
3 & 9 & 0.107 & -3.422 & 0.391 & 386.859 \\
4 & 9 & 0.484 & 17.332 & 0.037 & 329.115
\end{tabular}

The correlation $r^{2}$ measures the degree of the linear relationship between the independent variable (pitch/rolls) and the dependent variable (energy expenditure). $A$ represents the slope of the regression line and $P$ the level of significance. $B$ indicates where the regression line crosses the $y$-axis.
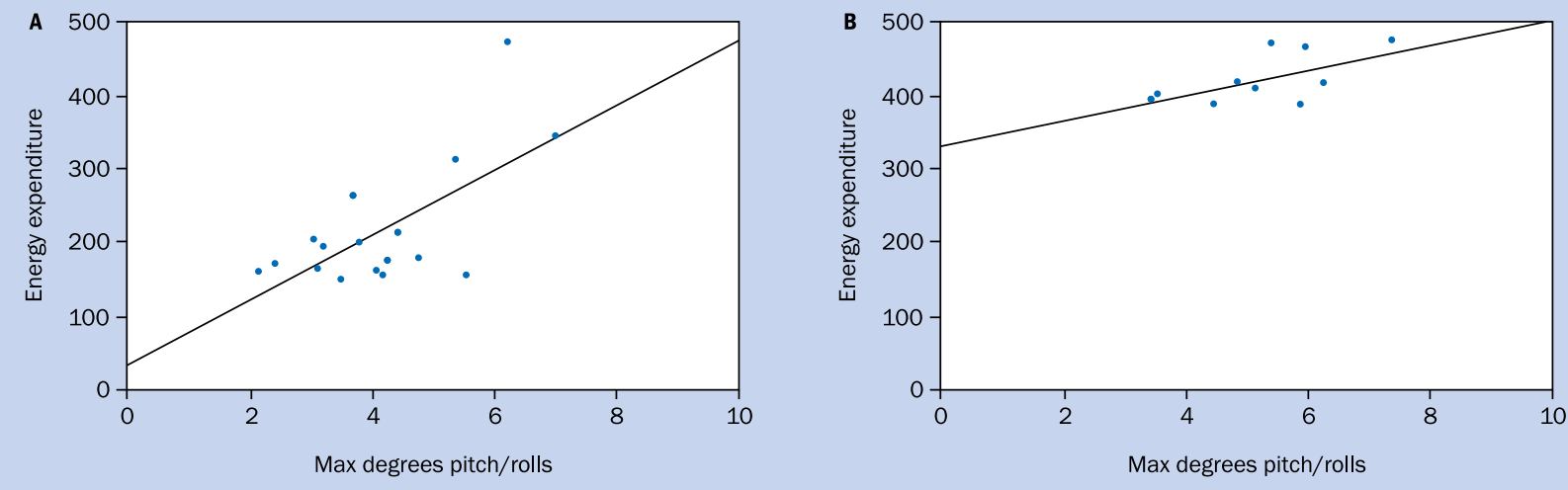

Figure 5. A. Navigation (upper quartile); B. Fishing (upper quartile) 
ries/day) was associated with higher energy expenditure $(p=0.034)$. Although the $r^{2}$ is high $(0.55)$ for the association, this finding should be considered with care due to few observations

The software, SenseWear professional 6.1 programme, is able to estimate activities such as sleep, supine position and steps taken, and permits correlation to the activities registered in the schemes. There was a high grade of consistence between those parameters (data not shown). Furthermore, the applied SenseWear system has been developed and optimised through continuous updates and evaluations of the algorithms for data analysis. Comparison of the outcomes with those of invasive methods that are regarded as gold standards [14, 15], e.g. the double labelled water stable isotope ( $2 \mathrm{H}, 180$ elimination) method and metabolic charts (oxygen and carbon dioxide inhalation and exhalation) have demonstrated a good validity of the instrument $[16,17]$. We are therefore rather confident that measurements of the energy expenditure were accurate.

The gyroscope applied in this study was constructed specifically for the Danish Fishermen's Occupational Health Service and meant for the evaluation of the vessels' stability and behaviour in terms of roll/pitch under different conditions of weather, waves and loads. The gyroscope has proved its value in terms of assessing the fishing vessel's stability, but no further testing of its validity has been performed. Therefore, a certain degree of inaccurate exposure measurements cannot be excluded.

Previous studies [1-3, 5-10] have demonstrated that keeping balance on the moving deck of a vessel increases the energy expenditure and consequently the metabolic rate of the fisherman. Several of these studies have compared the oxygen consumption of fishermen during various tasks on board - directly by the use of Douglas bags or indirectly by recording the heart rate, with laboratory measurements of their maximum oxygen uptake capacity on a mechanically braked bicycle ergometer. These studies have demonstrated mean levels at about $40 \%$ and peak levels at up to more than $70 \%$ of maximum capacity in fishermen engaged in ordinary working tasks on board $[3,8,9,17]$. These findings reflect a rather tough occupation in terms of physical demands, which, however, is far from those experienced with the weather conditions assessed in the present study.

The present pilot study is mostly descriptive in its nature. We have focused on the roll and pitch and ignored other potential effects on the fishermen's energy expenditure such as additional movements of the deck, e.g. whole body vibration and the effects of the ship's propulsion through the water. These exposure factors are likely to contribute by adding further to the total energy expenditure.
Further investigations are needed to verify our observations and, in particular, studies should be made in rough weather. Fishing vessels will behave differently at sea depending on their construction, size, applied catching methods and loads. For that reason, transferring the results to settings involving other vessels, fishing gear and catches may be limited.

\section{CONCLUSIONS}

We have analysed the energy expenditures for specific activities during fishing voyages and related them to the vessels' movements. In the present study, the calm weather conditions and consequently only minor vessel movements had little influence on the energy expenditure, which, however, could be demonstrated to be rather influenced by activities other than sleep on board. We have showed a good correlation to the expected and the actually measured energy expenditure during sleep.

\section{ACKNOWLEDGEMENTS}

We are grateful to Flemming Christensen, the Danish Fishermen's Occupational Health Service for kindly providing the gyroscopic equipment for measurements of the ships' movements and to Roberto Perissin, Sensotmedic Italy, BodyMedia for borrowing the SenseWear apparatus.

\section{REFERENCES}

1. Haward BM, Lewis $\mathrm{CH}$, Griffin MJ. Motions and crew responses on an offshore oil production and storage vessel. Appl Ergon, 2009; 40: 904-914.

2. Heus R, Wertheim AH, Havenith G. Human energy expenditure when walking on a moving platform. Eur J Appl Physiol Occup Physiol, 1998; 77: 388-394.

3. Rodahl K. [Occupational physiological examination of fishermen]. Nord Med, 1973; 88: 113.

4. Torner M, Zetterberg C, Anden U, Hansson T, Lindell V. Workload and musculoskeletal problems: a comparison between welders and office clerks (with reference also to fishermen). Ergonomics, 1991; 34: 1179-1196.

5. Torner M, Almstrom C, Karlsson R, Kadefors R. Working on a moving surface: a biomechanical analysis of musculo-skeletal load due to ship motions in combination with work. Ergonomics, 1994; 37: 345-362.

6. Torner M, Blide G, Eriksson H, Kadefors R, Karlsson R, Petersen I. Workload and ergonomics measures in Swedish professional fishing. Appl Ergon, 1988; 19: 202-212.

7. Dorval P. [Study of the workload of the fisherman]. Securite et conditions de travail à la peche maritime 1986.

8. Astrand I, Fugelli P, Karlsson CG, RodahI K, Vokac Z. Energy output and work stress in coastal fishing. Scand J Clin Lab Invest, 1973; 31: 105-113.

9. Nilsson S. [Danish seine fishing. A survey of the fishing and a study of the physiological work-load on the fishermen]. Tidsskr Nor Laegeforen, 1970; 90: 1375-1383.

10. Bilde G, Erikson H, Kadefors R, Karlsson R, Peterson I, Törner M. [Yarn, hook and seine fishing - workload and technical measures]. Lindholmen Utveckling, Gothenburg 2014. 
11. Åstrand I. Physical demands in worklife. Scand J Work Environ Health, 1988; 14 (suppl. 1): 10-13.

12. Jensen OC. Health hazards while fishing in heavy weather. Occup Environ Med, 1997; 54: 141.

13. BreidahI T, Christensen M, Jepsen JR, Johansen JP, Omland O. The influence of ship movements on the energy expenditure of fishermen. A study during a North Sea voyage in calm weather. Int Marit Health, 2013; 64: 114-120.

14. Wells JC, Fuller NJ. Precision and accuracy in a metabolic monitor for indirect calorimetry. Eur J Clin Nutr, 1998; 52: 536-540.
15. Johannsen DL, Calabro MA, Stewart J, Franke W, Rood JC, Welk GJ. Accuracy of armband monitors for measuring daily energy expenditure in healthy adults. Med Sci Sports Exerc, 2010; 42: 2134-2140.

16. Yates JW, Cullum M, Pittsley J. Validation of a portable indirect calorimeter for the measure of resting metabolic rate. Med Sci Sports Exerc, 2004; 36: S247.

17. Schoeller DA, Ravussin E, Schutz Y, Acheson KJ, Baertschi P, Jequier $E$. Energy expenditure by doubly labeled water: validation in humans and proposed calculation. Am J Physiol, 1986; 250: R823-R830. 